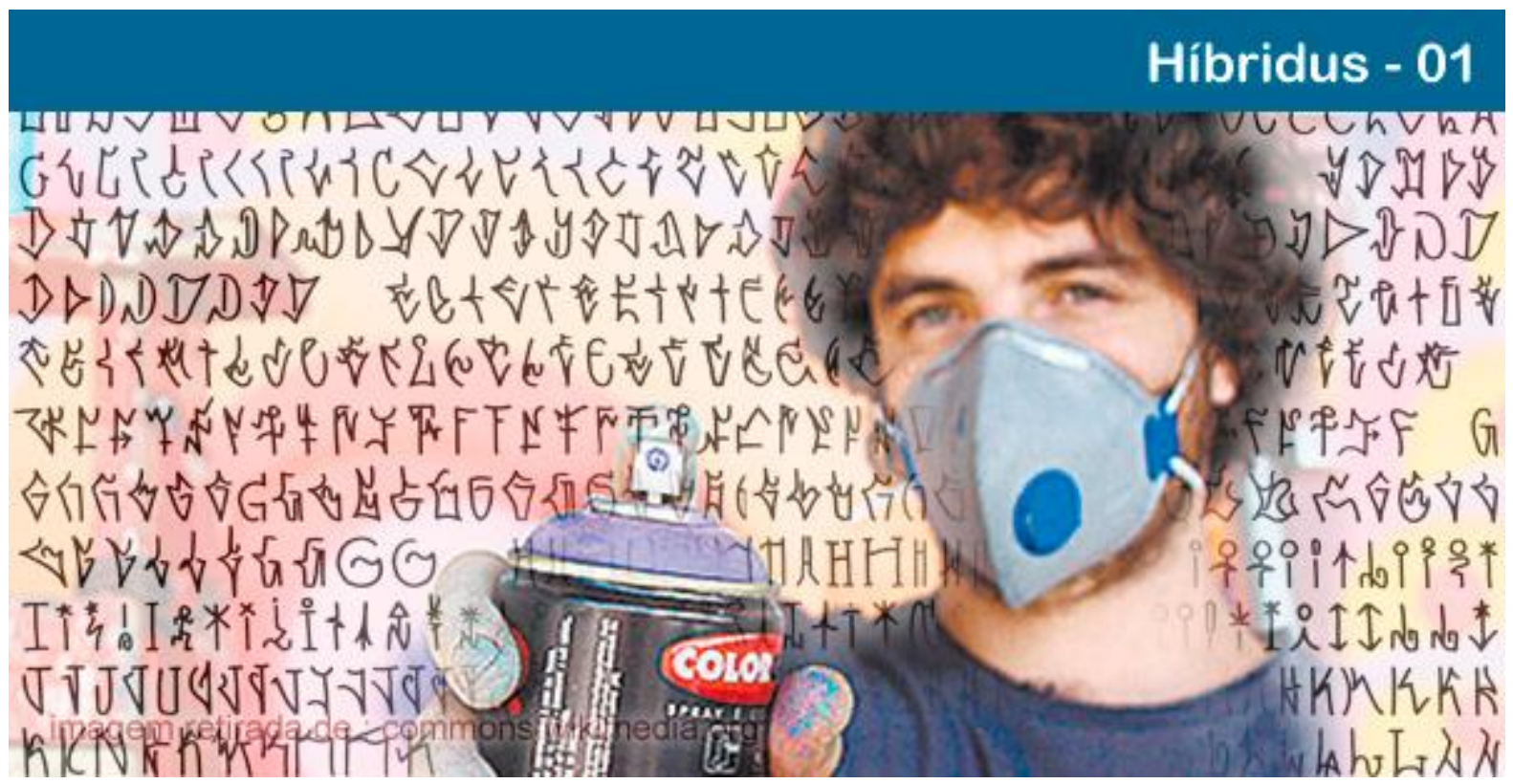

\title{
“SENTIR PARA ENTENDER": JUVENTUDE, PRESENÇA E SENTIDOS
}

\author{
Gustavo Coelho \\ Doutor em Educação. Professor Adjunto da Faculdade de Educação da Universidade do Estado do Rio de \\ Janeiro - UERJ. Professor do Programa de Pós-Graduação em Educação, Comunicação e Cultura em \\ Periferias Urbanas - FEBF/UERJ. E-mail: coelhoguga@gmail.com.
}

Resumo: A partir de alguns trechos de conversas com jovens praticantes de culturas marginalizadas de intensa corporeidade, tais como o funk e a piXação, notou-se que seus discursos buscavam na sensorialidade, nas sensações corporais, ou seja, em algo que de certo modo escapa aos seus controles racionais, os impulsos mais vitais aos seus fazeres, paradoxalmente, portanto, a "razão" mais fundante que os agita. Nessa espécie de franqueza jovem que reconhece, fora do reinado da racionalidade instrumental, uma dimensão também ativa naquilo que nos move, este artigo encontra material eloquente e os costura especialmente com o conceito de "presença" em Gumbrecht, a fim de atualizar empiricamente, em um cotidiano popular, os modos tanto discursivos quanto gestuais que, esquivando-se ao monopólio da clareza, parecem defender-se contra a ameaça do desencantamento, garantindo a intensidade necessária à boa fruição. Para tanto, Maffesoli, Jung, Foucault, Blanchot, entre outros, também - cada um a seu modo, mas todos em investimento crítico ao paradigma da modernidade, da consciência - formam a plataforma teórica.

Palavras-chave: Juventude. Epistemologia. Presença. Estética.

\section{"FEEL TO UNDERSTAND": YOUTH, PRESENCE AND MEANINGS}

Abstract: From some excerpts from conversations with young practitioners of marginalized cultures of intense corporeality, such as funk and piXação, it's noticed note that their speeches were seeking in sensuousness, in bodily sensations, in something that somehow escapes their rational control, the most vital impulses to their doings, paradoxically so, the most foundational "reason" that agitates them. In this kind of youth frankness that recognizes out of the reign of instrumental rationality, one dimension also active in what moves us, this article, then, finds eloquent materials and sews them especially with the concept of "presence" in Gumbrecht, in order to update empirically, in a popular enviroment, modes both discursive and gestural that, dodging the monopoly of clarity, seem to defend themselves against the threat of disenchantment, ensuring the necessary intensity to good fruition. Therefore, Maffesoli, Jung, Foucault, Blanchot, among others, also, each in their own way, but all in a critical investment to the paradigm of modernity, of consciousness, form the theoretical platform.

\section{POLÊM!CA $\mid$ LABORE (s:}

Polêmica - Revista Eletrônica da Uerj - Rua São Francisco Xavier, 524, $1^{\circ}$ andar

bloco D, sl.1001 • Tels.: +55 21 2334-4088 / 4087 • http://www.e-publicacoes.uerj.br/index.php/polemica/index

http://www.labore.uerj.br • laboreuerj@yahoo.com.br 
Keywords: Youth. Epistemology. Presence. Aesthetics.

O barulho da lata, o cheiro da tinta, hoje, isso faz parte da minha vida. (FYT piXador, em entrevista realizada em abril de 2010).

Quando eu senti o cheiro da tinta, acho que aquilo fisiologicamente mexeu comigo, porque na semana seguinte eu já estava indo para reuniões com lata de tinta. (RUNK - piXador, em entrevista realizada em abril de 2010).

Você tem que sentir o cheiro de suor, ficar sem camisa e colocar uma bermuda. Só assim você vai começar a entender (Babu - piXador e funkeiro, em conversa estabelecida em abril de 2013).

Talvez ele não te explique assim, a natureza da coisa, mas ele vai te dizer com convicção: "porque eu curto" (TATÁ - piXador, em entrevista realizada em maio de 2010).

A primeira vez que senti pertencer à Young Flu, eu nem tinha camisa, mas foi nas Laranjeiras. Ficar perto da torcida, sentir aquela sensação de encostar numa bandeira. Não tinha camisa, nem carteirinha ainda, mas lembro bem desse momento. (Fubá, torcedor organizado, ex-piXador e funkeiro, em entrevista realizada em julho de 2014).

Esses trechos nascidos de trabalho etnográfico no seio de uma rede de práticas culturais jovens e marginalizadas do Rio de Janeiro, mais especificamente a piXação, as torcidas organizadas, as turmas de bate-bola e galeras funk, um universo que, podemos dizer, compõe um mesmo cenário e mobiliza muitas vezes os mesmos jovens, são o disparo deste artigo, que tem por objetivo indicar pistas da franca aceitação da condição ativa que a dimensão sensorial, com tudo o que ela tem de enigmática, tem nessas vidas jovens marginalizadas. Seja pela embriaguez da tinta, pela dimensão poética do dorso nu e seu cheiro de suor, pela importância da simples bermuda, ou pela síntese preguiçosa do "porque eu curto", essa meninada zomba e embaralha os códigos já caducos, e parecem anunciar com a eloquência do que "sempre esteve por aí", a importância fundante do que sentem no modo como vivem, logo não permitindo ver nem sentir com definição a fronteira entre ética e estética. "Quero porque gosto", "faço porque vibro", "só sentindo pra entender", e nisso nos lançam num precipício. Urge, portanto, fazer dessa queda livre, uma boa descida expedicionária. Nessa descida, então, junto com piXadores, torcedores, bate-bolas e funkeiros, estou também acompanhado por outros que empreenderam essa mesma tarefa paradoxal de pensar a dimensão do impensado. Para o momento, trago Gumbrecht (2010) que investiu numa crítica ao reinado da interpretação, entendido pela tradição moderna como única dimensão produtora de conhecimento sobre a humanidade, defendendo, por outro lado,

\section{POLÊM!CA $\mid$ LABORE}


que há, na própria fisicalidade do mundo, na sua "presença", no que há de "tangível", um elemento determinante na nossa relação com o mundo, conferindo, assim, à experiência estética, ou seja, ao corpo vibrátil empírico, uma capacidade, por tanto tempo negligenciada, de fazer florescer saberes que não necessariamente terão sua expressão naquela que foi a forma por excelência legitimada de enunciação - a verbalização lógica e clara, representativa, portanto. Se há o reconhecimento, então, de que a primazia da racionalidade cognitivoinstrumental jogou o véu da invisibilidade e da desqualificação sobre saberes que operassem em outras frequências, será preciso reconhecer também que não só sua gestação opera nessas outras lógicas subalternizadas, mas também, sua expressividade pode não se dar pela interpretação verbal representativa de intuito esclarecedor, ferramenta por excelência da dominação do mundo pela "atribuição de sentidos", vocação para a qual nascem, como bem aponta Gumbrecht, as Ciências Humanas, em resposta a qual, ele propõe essa noção de presença.

"O prazer da presença é a fórmula mística por excelência”, e uma presença que escapa à dimensão do sentido tem de estar em tensão com o princípio da representação: "A presença não vem sem apagar a presença que a representação gostaria de designar (os seus fundamentos, a sua origem, o seu tema)." (GUMBRECHT, 2010, p. 82).

Escapar, então, da lógica da apreensão da vida pelas ferramentas dissecantes da atribuição de sentido, parece ser movimento muito frequente na maneira como esses jovens que pesquiso relacionam-se com o que fazem. Exigência de uma epistemologia mais do sensível que do sentido, então, que parece também ter sido apontada como característica do que emerge criticamente em nossa época, tanto por Maffesoli quanto por Bauman: A experiência, seja ela qual for, encerra uma potencialidade cognitiva. A
demarcação pode ser uma noção peculiar à politica, à moral ou a certa forma de
ciência - mas não serve, de modo algum, para a definição do conhecimento.
(MAFFESOLI, 2007, p. 199).

Estamos também aprendendo a viver com a revelação de que não se pode articular tudo o que se sabe, e de que compreender - saber como proceder - nem sempre requer a disponibilidade de um preceito verbalizado. (BAUMAN, 1998, p. 208).

Sensibilidade que me parece muito próxima dos valores atribuídos por esses jovens à rua como fonte inesgotável de conhecimentos que, no entanto, não são facilmente descritíveis, ou melhor, que só podem ser bem compreendidos se mantida essa elasticidade do

\section{POLÊM!CA $\mid$ LABORE}


indescritível. É na rua, então, que por excelência se anuncia, mesmo que em forma de enigma, a "tendência" de uma época, ainda que diante dela, sejam as categorias consolidadas numa época anterior, já incompatíveis, que ainda predominantemente sejam convocadas nas tentativas conscientes de compreensão. Em suma, na rua só cabe intuição, enquanto que nos discursos oficiais ocupados em apreendê-la com as ferramentas do sentido, só pode haver expressão explicativa. Sabedoria da rua que Blanchot soube bem reconhecer:

Será uma metáfora? Ela nos sugere algo de importante e de perturbador: é que estamos no final de um discurso e que, ao passar para um outro, continuamos a exprimir-nos pela comodidade de uma velha linguagem sem conveniência. Eis o perigo maior. É, inclusive, o único. A rua é portanto bem mais sábia do que os pensadores cuidadosos que esperam ter novas categorias para pensar o que ocorre. Eu o faria notar que os teólogos falaram alguma vez do "odor de fim de tempo", de uma espécie de experiência sui generis que, nos fenômenos históricos reais, permitiria discernir a abertura, o ser rumando para o fim. (BLANCHOT, 2007, p. 276).

Uma rua que é preciso frequentar para "sentir" o aprendizado; este de um tipo que não se encontra com evidência em parte alguma, mas está por toda parte. Muitas vezes a chamam de "pista"; ao convidar o amigo para sair, utilizam a expressão significativa "vamos cair pra pista?". Assim, analogamente, ao que me parece, convidando a "deixar-se cair", eles transferem o dinamismo e o ambiente onde a segurança de si se dissolve, próprio dos bailes e festas, à rua.

Porra, a rua é uma escola, uma escola de vida. Tem muita coisa, muita coisa, que eu não falo pro meu filho, que meu pai não falou pra mim, que meu filho aprende na rua, entendeu? É uma coisa que já está ali na rua, não está na casa de ninguém. $\mathrm{Na}$ rua, você aprende a malandragem, você aprende a olhar as pessoas, você aprende aonde você vai pisar, é na rua. (Hair, piXador, em entrevista realizada em março de 2009).

A rua é como se fizesse parte do meu corpo, quando eu piso no chão é uma coisa só. Rua é rua, não tem jeito. (Nuno, piXador e ex-torcedor organizado, em entrevista realizada em maio de 2009).

Eu sempre fiz luta desde pequeno. Judô, karatê e a que eu mais me identifiquei foi o Taekwondo. Mas você não vai acreditar, eu diria que ela nunca influenciou nas brigas porque são modos completamente diferentes. O estilo de rua, a street fight é diferente de arte marcial. Acho que o que eu aprendi na rua ajudou muito mais na academia, do que o que eu aprendi na academia, na rua. Você fica mais duro, mais maldoso, mais calejado, você não vai se amedrontar, entendeu? (Fubá, torcedor organizado, ex-piXador e funkeiro de baile de corredor, em entrevista realizada em julho de 2014).

\section{POLÊM!CA $\mid$ LABORE}

Polêmica - Revista Eletrônica da Uerj - Rua São Francisco Xavier, 524, $1^{\circ}$ andar

bloco D, sl.1001 • Tels.: +55 21 2334-4088 / 4087 • http://www.e-publicacoes.uerj.br/index.php/polemica/index

http://www.labore.uerj.br • laboreuerj@yahoo.com.br 
Nesse sentido, e fazendo a analogia com o nosso campo em particular, a piXação, as torcidas, o baile, as turmas de bate-bola e todo o repertório estético do jovem popular são em si mesmo, enquanto "presença" inexorável e inegável na cidade, catalisadores de conhecimento e determinantes na experiência de estar na cidade. Sendo assim, a presença do fenômeno é tão ou mais importante que aquilo que se fala dele, tanto o é que, como pudemos ver, quando indagados sobre as razões de suas práticas, esses meninos e meninas praticantes lançam mão frequentemente de metáforas sensoriais, a fim de produzir um efeito dessa "presença" em quem os ouve, servindo-se, para isso, mais do enigma da poesia que da explicação clarificante. Nesse caso, o próprio discurso pretende funcionar como "presença", impedindo que a experiência seja ameaçada por um único sentido, e dando, para isso, lugar devido à fisicalidade como fator determinante para uma compreensão composta da cultura. Trata-se, portanto, menos de saber o que pensam e mais de sentir o que sentem, recolocando em cena assim a corporeidade, dimensão negada para a invenção do homem incorpóreo moderno. Parece-me, então, justamente o que Gumbrecht (2010, p. 15) diz: "No entanto, só os efeitos de presença apelam os sentidos - por isso, as reações que provocam não têm nada a ver com Einfühlung, isto é, com imaginar o que se passa no pensamento de outra pessoa".

Daí se pode deduzir bem a relação que proponho entre as formas de lidar com a vida, de propriamente viver desses jovens, e a sensibilidade trágica que, a meu ver, encenam obscenamente. Ao, então, parecerem aceitar a dimensão obscura da vida, paradoxalmente afirmam a clarividência quanto à presença dessa obscuridade, não fazendo mais, portanto, do contraditório uma impossibilidade, como o fez a ideia progressista de mundo na obsessão por um futuro ideal despregado de equívocos, de contradições, de paradoxos, de inconsciente, de enigmas. Para envolver essa questão, vamos a Blanchot (2007), que inclusive entendeu esse homem trágico como quem desaparece com os equívocos, não para sobrepô-los com uma explicação esclarecida, mas indo além, por ter à sua volta a extrema contrariedade, esse homem suplanta a própria qualidade de equívoco, como que "do sim e não confusamente misturados aos sim e não claramente mantidos em sua oposição" (p. 31):

É que, buscando, ele[, o homem trágico,] encontrou aquilo que, infinitamente fora dele e acima dele, mantém reunidas, em um acontecimento inicial, a maior clareza e a maior obscuridade, unidade incompreensível frente à qual está de agora em diante, tudo mudado nele e à sua volta por essa medida de extrema contrariedade que faz desaparecer os equívocos. (BLANCHOT, 2007, p. 32).

\section{POLÊM!CA $\mid$ LABORE}


Nisso, então, nessa elevação conjunta e afirmativa dos contrários, se por um lado ela pode ser de certa forma testemunhada em atos na performance de vida desses jovens, por outro, encontra na linguagem verbal um aparelho de difícil expressão, haja vista que este, como veremos, em sua mais corrente forma de construção de linhas de raciocínio lógico parece funcionar mais pelo contraste antitético entre os contrários do que numa caleidoscópica, ou mosaica, afirmação dos extremos, como nos indica Nietzsche acerca da maior familiaridade entre o "mito trágico" e o "em ato" do que com os discursos.

\begin{abstract}
Ao mesmo tempo, porém, devemos confessar que o alcance do mito trágico, tal como o estabelecemos, nunca foi percebido com uma clareza manifesta pelos poetas gregos e menos ainda pelos filósofos gregos; a linguagem de seus heróis é, sob certos aspectos, mais superficial que seus atos; o mito não encontra de forma alguma no discurso sua objetivação adequada. A sucessão das cenas e o espetáculo dos quadros proclamam uma sabedoria mais profunda que aquela que é possível ao próprio poeta atingir por meio das palavras e dos conceitos. (NIETZSCHE, 2007, p. 119-120).
\end{abstract}

Por essa via, portanto, nessa elevação do "ato" como protagonista dessa epistemologia em franca gestação nos cotidianos desses jovens e, como já propusemos, das tendências críticas de nossa época, é possível compreender a prevalência do presente, uma vez que única dimensão possível ao acontecimento do "em ato". Nisso, então, vemos todas as características que são de exclusividade do presente, ou seja, as sensações, os prazeres, a ambiência, as emoções, as experiências estéticas, transbordar "dos poros ao sopro" (PACHECO, 2012) da fala, fazendo desta mais fonte de expressão das sensações vividas, com tudo o que elas têm de ambivalente, do que de análise do vivido e planificação de futuro, com tudo o que essas iniciativas têm de vontade de esclarecimento. Nesse mesmo caminho, Gumbrecht descreve muito bem o protagonismo da noção de tempo na solidificação da racionalidade moderna, assim como de espaço nas culturas que confiram maior centralidade à noção de presença:

[...] o espaço - ou seja, a dimensão que se constitui ao redor dos corpos - deve ser a dimensão primordial em que se negociem a relação entre os diferentes seres humanos e a relação entre os seres humanos e as coisas do mundo. Em contrapartida, o tempo é a dimensão primordial em qualquer cultura de sentido, pois parece existir uma associação inevitável entre a consciência e a temporalidade (lembre-se o conceito husserliano de "corrente de consciência"). Acima de tudo, porém, o tempo é a dimensão primordial em qualquer cultura de sentido, pois leva tempo para concretizar as ações transformadoras por meio das quais as culturas de sentido definem a relação entre os seres humanos e o mundo. (GUMBRECHT, 2010, p. 110).

\title{
POLÊM!CA $\mid$ LABORE
}

Polêmica - Revista Eletrônica da Uerj - Rua São Francisco Xavier, 524, $1^{\circ}$ andar

bloco D, sl.1001 • Tels.: +55 21 2334-4088 / 4087 • http://www.e-publicacoes.uerj.br/index.php/polemica/index

http://www.labore.uerj.br • laboreuerj@yahoo.com.br 
Esse trecho já nos permite apresentar a distinção nodal que Gumbrecht forja como espécies de categoriais didáticas no manejo e estudo dessas duas dimensões - "culturas de presença" e "culturas de sentido". A primeira mais aberta ao inconsciente, a segunda mais limitada à consciência, a primeira consagrando o corpo, a segunda a mente, a primeira privilegiando o Regime Noturno do Imaginário, a segunda o Diurno (DURAND, 2002), a primeira funcionando mais por justaposição, a segunda por sucessão. Em todo caso, ainda que seja preciso assumir que essas dicotomias parecem confortar nossas vontades explicativas e didáticas, afinal a própria lógica de "fazer pesquisa" é uma instituição de uma cultura de sentido, à qual estamos, querendo ou não, vinculados, Gumbrecht preocupa-se em, por diversas vezes durante sua obra, apontar a condição complexa e gradual dessa distinção, não havendo, portanto, para ele, nenhuma cultura exclusivamente de sentido, nem alguma outra regida apenas pela presença, sendo tanto uma quanto outra, impossibilidades patentes.

Penso que todas as culturas podem ser analisadas como configurações complexas, cujos níveis de autorreferência congregam componentes de cultura de sentido e de cultura de presença (assim como defendo que em todos os objetos culturais podemos discernir efeitos de sentido e efeitos de presença). (GUMBRECHT, 2010, p. 106).

Trata-se, então, mais de uma questão de gradação e possível intimidação em uma eterna oscilação entre as duas dimensões, do que propriamente escolher um dos partidos e vislumbrar uma sociedade ideal regida por um deles, movimento que já seria apenas possível pelo monopólio da cultura do sentido, diga-se de passagem. Em todo caso, Gumbrecht estava ciente dos efeitos dessa oscilação não apenas ao nível do conceito, mas de sua própria experiência, quando chegou a utilizar a primeira pessoa do singular para dizer:

Constantemente receio que os efeitos de sentido (ou, pelo menos, uma overdose deles) possam reduzir meus momentos de presença - mas sei, ao mesmo tempo, que a presença nunca seria perfeita se o sentido fosse excluído. Mesmo que o sentido nunca surja sem produzir efeitos de distância, também é verdade que eu não poderia estar "ali", completamente na minha existência, se o sentido estivesse fora de questão. (GUMBRECHT, 2010, p. 169).

Sendo assim, ainda que na prática essas ondas colonizatórias, essas da qual a consolidação de um paradigma epistemológico centrado no sentido é um dos frutos, tenham de fato investido na extinção de uma série de matrizes culturais assentadas na presença, que vastos conhecimentos tenham sido extintos e dos quais sequer tenhamos mais notícias, ainda assim, não é possível haver uma ditadura do sentido que de maneira definitiva encerre o

\section{POLÊM!CA $\mid$ LABORE}


mundo em seus limites. Há sempre uma reserva de resistência à transformação total, uma gravidade teimosa. Arrisco assim dizer que há uma predisposição contemporânea nessas culturas jovens, mas certamente não só nelas, em indicar pelo seu cotidiano, pelo seu estilo de vida e, paradoxalmente, mesmo em muitos dos seus pensamentos que a predominância do sentido relaxou, encontra-se em estado de crise por saturação. Nesses cotidianos, então, como estamos vendo, já se "sabe" que aquilo que se consegue pensar não sintetiza por completo o ser que pensa, que a dimensão pensante do ser, portanto, não o encerra e nem depende exclusivamente do que é controlável por "ele" para emergir, muito embora isso não seja sempre confessado. Jovens, então, que põem a noção de "ser" moderno em questão exatamente como o fez Foucault em As palavras e as coisas (2007), quando, a partir inclusive de um vocabulário psicanalítico, percebe na gradativa aceitação da existência de um inconsciente pelo homem de sua época, um indicativo de importantes mudanças epistemológicas em curso, apontando com isso, as limitações do cogito cartesiano, ancorado no reforço do pensamento como atividade que garantiria a "segurança" da "instituição" indivíduo, numa luta mesmo contra o que nele há de ilusório, de não-pensado; nas palavras de Foucault:

É que, para Descartes, tratava-se de trazer à luz o pensamento como forma mais geral de todos esses pensamentos que são o erro ou a ilusão, de maneira a conjurarlhes o perigo, com o risco de reencontrá-los no final de sua tentativa, de explicá-los e de propor então o método para evitá-los. No cogito [contemporâneo], trata-se, ao contrário, de deixar valer, na sua maior dimensão, a distância que, a um tempo, separa e religa o pensamento presente a si, com aquilo que, do pensamento, se enraíza no não-pensado. (FOUCAULT, 2007, p. 446-447).

Ou ainda aqui quando Foucault sugere que a crença num pensamento objetivo, ao ser levado a pensar sobre o próprio ato de pensar, tomando, portanto, a psique humana em toda sua extensão como decodificável por princípio, levaria, caso de fato fosse possível alcançar esse objetivo, ao desaparecimento, por esgotamento de objeto, do próprio pensamento desse tipo reflexivo, voltado sobre si:

Tem-se facilmente a impressão de que, a partir do momento em que o homem se constituiu como uma figura positiva no campo do saber, o velho privilégio do conhecimento reflexivo, do pensamento que se pensa a si mesmo, não podia deixar de desaparecer; mas que era, por isso mesmo, dado a um pensamento objetivo percorrer o homem por inteiro - com o risco de neles descobrir o que precisamente jamais poderia ser dado à sua reflexão nem mesmo à sua consciência: mecanismos obscuros, determinações sem figura, toda uma paisagem de sombra a que, direta ou indiretamente, se chamou inconsciente. (FOUCAULT, 2007, p. 450).

\section{POLÊM!CA $\mid$ LABORE}

Polêmica - Revista Eletrônica da Uerj - Rua São Francisco Xavier, 524, $1^{\circ}$ andar

bloco D, sl.1001 • Tels.: +55 21 2334-4088 / 4087 • http://www.e-publicacoes.uerj.br/index.php/polemica/index

http://www.labore.uerj.br • laboreuerj@yahoo.com.br 
Pois bem, esse pensamento não-dirigido, composto em sua maior parte pelos elementos de nosso inconsciente, esse tipo que nos toma de forma involuntária, e cuja forma por excelência é o sonho, compõe-se de toda uma sorte de narrativas imagéticas repletas de absurdos, imoralidades, desvios e surrealismos, por vezes vergonhosos a nós mesmos, mas que a gente consegue obliterar por se dar no íntimo invisível. No entanto, por outro lado, quando a expressão desse não-dirigido, desse não-pensado, vez ou outra passa pelas máquinas de vigilância da consciência, emerge, e se dá inscrita no ambiente, ou seja, ao redor do, ou no corpo, os vestígios dessas obras involuntárias passam a ser viscosos, ficam, deixam marcas, resíduos visíveis, odores, manchas. São presenças. Como tão bem expressou Nelson Rodrigues em sua peça Toda nudez será castigada, quando o personagem Patrício zomba de Herculano e, imaginando se suas tias examinassem suas cuecas, diz "E viram, pelas cuecas, que você é homem, o teu desejo pinga! Você é homem, homem, homem”. Se tomarmos então essa imagem como uma metáfora do corpo societal, e nesse caso não há erro ortográfico, trata-se mesmo do conceito de societal elaborado no decorrer de diversas obras por Maffesoli que, em oposição ao social, que seria "apenas um estar junto racional, [sendo] a sociabilidade [...] a expressão natural desse social baseado na racionalidade” (MAFFESOLI, 2011, p. 47), introduziria uma outra dimensão "em funcionamento em nossa espécie animal. [...] Lógica [que] não pode ser reduzida a coisa alguma. E muito menos à razão, à consciência, ao indivíduo, [...] uma lógica do que está entre-dois, ou seja, do que é múltiplo" (MAFFESOLI, 2007, p. 12). Nesse caso, então, aquele pingo, cuja mancha nunca sai completamente, seria metáfora dos transbordamentos estéticos dessas vidas jovens que me interessam, os piXos, as danças de bate-bola, os gritos de torcida, os excessos dos bailes funk, enquanto que a cueca aqui faria referência ao mundo ou à cidade se preferirmos, nutrida em grande parte por esses respingos. Mantendo-se na questão do corpo, então, mas voltando a Gumbrecht, sem tanta dramaturgia é claro, ele também sugere esse corpo "tocado" como alvo de uma negação que foi necessária para que se pudesse elevar o pensamento dirigido como exclusiva dimensão do que seria humano, repressão que teve um alto custo.

[...] qualquer forma de comunicação, com seus elementos materiais, "tocará" os corpos das pessoas que estão em comunicação de modos específicos e variados mas não deixa de ser verdade que isso havia sido obliterado (ou progressivamente esquecido) pelo edifício teórico do Ocidente desde que o cogito cartesiano fez a

\section{POLÊM!CA $\mid$ LABORE}

Polêmica - Revista Eletrônica da Uerj - Rua São Francisco Xavier, 524, $1^{\circ}$ andar

bloco D, sl.1001 • Tels.: +55 21 2334-4088 / 4087 • http://www.e-publicacoes.uerj.br/index.php/polemica/index

http://www.labore.uerj.br • laboreuerj@yahoo.com.br 
ontologia da existência humana depender exclusivamente dos movimentos do pensamento humano. (GUMBRECHT, 2010, p. 39).

Pode-se advogar dizendo que não seria um privilégio nem do Ocidente e nem da Modernidade, esse desenvolvimento de uma instância moral crítica que atue gerindo essa dimensão nunca completamente controlável que é o não-pensado, a fim de preservar o "eu" dos perigos inerentes a esses nublados "outros" que o compõem. No entanto, talvez a intensidade alcançada pela hipertrofia do "eu" moderno ocidental tenha chegado a níveis tão extravagantes que foi possível crer, cartesianamente, que, pelo "pensamento", superaríamos por definitivo o impacto do não-pensado, não deixando mais espaço nem lugar aos perigos do ilusório e do fantástico. Parece-me que mesmo Jung e Freud, representantes por excelência da psicanálise - campo da ciência que, digamos, "fez a curva" ao investir no "pensamento sobre o não-pensado" -, concordaram quanto a isso. O primeiro, atribuindo à tal mentalidade moderna a "qualidade" de "burrice esclarecida" (JUNG, 2011, p. 72), e o segundo, nas últimas linhas de seu célebre trabalho sobre $O$ mal-estar na civilização, a partir de uma espécie de neurose do controle na sociedade europeia, prevê que justamente nisso está potencialmente o germe de sua autodestruição: "Precisamente quanto a isso a época de hoje merecerá talvez um interesse especial. Atualmente os seres humanos atingiram um tal controle das forças da natureza, que não lhes é difícil recorrerem a elas para se exterminarem até o último homem" (FREUD, 2011, p. 93).

No entanto, como disse, há um custo que se paga por tão fraca assimilação do inconsciente coletivo pelo corpo social, e esse "Mal", que se preferiu crer ter sido possível extirpar, recobra seu espaço. Um "Mal" que insurge provocando crise, uma vez que funciona sobre outras bases epistemológicas, diante das quais o homem desenvolvido no sistema epistêmico ocidental parece atrofiado na sua capacidade de perceber seu "lugar" - percepção que, como Maffesoli bem mostra, segue atuante especialmente nos cotidianos populares, alimentando boa parte de seus saberes comuns, humildes no reconhecimento de que nem tudo cabe "em suas mãos”.

O confronto com o mundo subterrâneo é mesmo encarado como um momento necessário para o que é considerado um "ser-mais" em devir. As expressões populares "Há males que vêm para o bem", "O mundo tem lugar para tudo" etc. não se enganam ao estabelecerem uma sinergia entre todos os componentes do dado mundano. (MAFFESOLI, 2004, p. 41-42).

\section{POLÊM!CA $\mid$ LABORE}


É, a meu ver, portanto, desse mesmo reconhecimento, central nesses ditos populares, que essas práticas jovens se nutrem para produzir suas radicalidades. Uma juventude que, portanto, através de sua performance, do que faz, de como vive, de sua constelação imagética, dá variadas formas a esse disforme não-pensado. Sem lhe conferir um sentido único e sem também autoatribuir-se a posse do mesmo, ela o faz enigma presente. Não investe na sua explicação, o que seria seguir perpetuando as bases epistemológicas caducas da modernidade. Pelo contrário, protege-se dessa tendência exacerbando a presença, a forma, o fantástico. A "explicação" das razões porque sou piXador, torcedor, funkeiro ou bate-bola concentra-se mais na tinta no muro, no rojão da torcida, no corredor do baile e na fantasia, ou melhor, reconhecendo a potência do conceito de Gumbrecht (2010), encontra na materialidade da "presença" influência e reverberações decisivas ao destino. Talvez, então, na recusa da posse das razões explicativas, na negação da autoria da escolha, nos cheiros e barulhos como intuitivas dimensões responsáveis pelo ato de piXar, na sensorialidade do suor e da bermuda como forma de entendimento, e na sensação do toque na bandeira como memória que sobreviveu ao tempo e acumula os dados imaginários da associação à torcida, estejam imagens eloquentes quanto a esse estado de relaxamento que esses jovens imputem ao pensamento dirigido, garantindo sua elasticidade e a abertura de fissuras em seu tecido geralmente rígido, por onde escapam com mais facilidade e se fazem presença, o fantástico, o subterrâneo, o emotivo, o inconsciente, o enigma. Finalizo, então, dizendo isso em companhia de Jung:

Um enfraquecimento do interesse, um leve cansaço, é suficiente para anular a adaptação psicológica exata ao mundo real, que se manifesta pelo pensamento dirigido e substituí-la por fantasias [...]; se a desatenção aumenta, perdemos pouco a pouco a consciência do presente e a fantasia domina. (JUNG, 2011, p. 46).

\section{Referências}

BAUMAN, Zygmunt. O mal-estar da pós-modernidade. Rio de Janeiro: Zahar, 1998.

BLANCHOT, Maurice. A conversa infinita 2: a experiência limite. São Paulo: Escuta, 2007.

DURAND, Gilbert. As estruturas antropológicas do imaginário: introdução à arquetipologia geral. 3. ed. São Paulo: Martins Fontes, 2002.

FOUCAULT, Michel. As palavras e as coisas: uma arqueologia das ciências humanas. São Paulo: Martins Fontes, 2007.

FREUD, Sigmund. O mal-estar na civilização. São Paulo: Penguin Classics Companhia das Letras, 2011.

\section{POLÊM!CA $\mid$ LABORE}

Polêmica - Revista Eletrônica da Uerj - Rua São Francisco Xavier, 524, $1^{\circ}$ andar

bloco D, sl.1001 • Tels.: +55 21 2334-4088 / 4087 • http://www.e-publicacoes.uerj.br/index.php/polemica/index

http://www.labore.uerj.br • laboreuerj@yahoo.com.br 
GUMBRECHT, Hans Ulrich. Produção de presença: o que o sentido não consegue transmitir. Rio de Janeiro: Contraponto: Ed. PUC-Rio, 2010.

JUNG, Carl Gustav. Símbolos da transformação: análise dos prelúdios de uma esquizofrenia. 7. ed. Petrópolis: Vozes, 2011.

MAFFESOLI, Michel. A parte do diabo. Rio de Janeiro: Record, 2004.

O ritmo da vida: variações sobre o imaginário pós-moderno. Rio de Janeiro: Record, 2007.

Quem é Michel Maffesoli: entrevistas com Christophe Bourseille. Petrópolis: De Petrus et Alii, 2011.

NIETZSCHE, Friedrich. O nascimento da tragédia. São Paulo: Escala, 2007.

PACHECO, Elizabeth Medeiros. Dos poros ao sopro: uma crítica ao paradigma identitário. 2009. 126f. Tese (Doutorado em Psicologia Clínica) - Programa de Pós-Graduação em Psicologia Clínica - Pontifícia Universidade Católica de São Paulo, São Paulo, 28 de maio de 2012.

Recebido em: 30/06/2016.

Aceito em: 30/09/2016.

\section{POLÊM!CA LABORE}

